\title{
Prevalence and type of cervical deformities among adults with Parkinson's disease: a cross-sectional study
}

\author{
${ }^{*}$ Bong Ju Moon, MD, ${ }^{1}$ Justin S. Smith, MD, PhD, ${ }^{2}$ Christopher P. Ames, MD, ${ }^{3}$ \\ Christopher I. Shaffrey, MD, ${ }^{2}$ Virginie Lafage, PhD, ${ }^{4}$ Frank Schwab, MD, ${ }^{4}$ Morio Matsumoto, MD, ${ }^{5}$ \\ Jong Sam Baik, MD, ${ }^{6}$ and Yoon $\mathrm{Ha}, \mathrm{MD}, \mathrm{PhD}^{7}$
}

\begin{abstract}
'Department of Medicine, Graduate School of Yonsei University, Seoul, Korea; ${ }^{2}$ Department of Neurological Surgery, University of Virginia Health System, Charlottesville, Virginia; ${ }^{3}$ Department of Neurosurgery, University of California, San Francisco, California; ${ }^{4}$ Department of Orthopaedic Surgery, NYU Hospital for Joint Diseases, New York, New York; ${ }^{5}$ Department of Orthopaedic Surgery, School of Medicine, Keio University, Tokyo, Japan; and ${ }^{6}$ Department of Neurology, Sanggye Paik Hospital, Inje University College of Medicine, and 'Department of Neurosurgery, College of Medicine, Yonsei University, Seoul, Korea
\end{abstract}

\begin{abstract}
OBJECT To identify the characteristics of cervical deformities in Parkinson's disease (PD) and the role of severity of $\mathrm{PD}$ in the development of cervical spine deformities, the authors investigated the prevalence of the cervical deformities, cervical kyphosis (CK), and cervical positive sagittal malalignment (CPSM) in patients with PD. They also analyzed the association of severity of cervical deformities with the stage of PD in the context of global sagittal spinopelvic alignment.

METHODS This study was a prospective assessment of consecutively treated patients $(n=89)$ with PD. A control group of the age- and sex-matched patients was selected from patients with degenerative cervical spine disease but without PD. Clinical and demographic parameters including age, sex, duration of PD, and Hoehn and Yahr (H\&Y) stage were collected. Full-length standing radiographs were used to assess spinopelvic parameters. CK was defined as a C2-7 Cobb angle $<0^{\circ}$. CPSM was defined as C2-7 sagittal vertical axis (SVA) $>4 \mathrm{~cm}$.
\end{abstract}

RESULTS A significantly higher prevalence of CPSM (28\% vs $1.1 \%, p<0.001)$, but not CK (12\% vs $10.1 \%, p=0.635)$, was found in PD patients compared with control patients. Among patients with PD, those with CK were younger (62.1 vs 69.0 years, $p=0.013$ ) and had longer duration of PD (56.4 vs 36.2 months, $p=0.034)$, but the severity of PD was not significantly different. Logistic regression analysis revealed that the presence of CK was associated with younger age, higher mismatch between pelvic incidence and lumbar lordosis, and lower C7-S1 SVA. The patients with CPSM had significantly greater thoracic kyphosis (TK) $(p<0.001)$ and a trend toward more advanced H\&Y stage $(p=0.05)$. Logistic regression analysis revealed that CPSM was associated with male sex, greater TK, and more advanced H\&Y stage.

CONCLUSIONS Patients with PD have a significantly higher prevalence of CPSM compared with age- and sexmatched control patients with cervical degenerative disease but without PD. Among patients with PD, CK is not associated with the severity of PD but is associated with overall global sagittal malalignment. In contrast, the presence of CPSM is associated more with the severity of PD than it is with the presence of global sagittal malalignment. Collectively, these data suggest that the neuromuscular pathogenesis of PD may affect the development of CPSM more than of CK.

http://thejns.org/doi/abs/10.3171/2015.6.SPINE141197

KEY WORDS Parkinson's disease; cervical kyphosis; cervical positive sagittal malalignment; deformity

$\mathrm{P}$ ARKINSON's disease (PD) is a degenerative neurological condition characterized by tremor, rigidity, bradykinesia, and loss of postural reflexes. In addition, a postural deformity is often present in patients with PD. A retrospective observational study has suggested that up to one-third of patients with PD exhibit a postural defor- mity. ${ }^{2}$ The overall prevalence of spinal deformities in PD has been reported to be higher than that of age-matched adults without PD. ${ }^{20}$ Patients with PD may also have concomitant neuromuscular and degenerative diseases that can lead to spinal deformities. ${ }^{5}$

The abnormal posture that often accompanies PD may

ABBREVIATIONS CK = cervical kyphosis; CPSM = cervical positive sagittal malalignment; $\mathrm{H} \& Y=$ Hoehn and Yahr; HRQOL = health-related quality of life; LL = lumbar Iordosis; PD = Parkinson's disease; PI = pelvic incidence; $\mathrm{PT}$ = pelvic tilt; SRS = Scoliosis Research Society; SVA = sagittal vertical axis; TK = thoracic kyphosis; UPDRS = Unified Parkinson's Disease Rating Scale.

SUBMITTED December 8, 2014. ACCEPTED June 11, 2015.

INCLUDE WHEN CITING Published online December 11, 2015; DOI: 10.3171/2015.6.SPINE141197.

* Drs. Moon and Smith contributed equally to this work. Drs. Baik and Ha share senior authorship of this work. 
result in spinal deformity, such as camptocormia, antecollis (drop head syndrome), Pisa syndrome, and scoliosis. Antecollis has a reported prevalence of approximately $6 \%$ in $\mathrm{PD},{ }^{2,6}$ and, when severe, the neck drop of antecollis can be markedly more pronounced relative to the expected flexed posture of the trunk and limbs. ${ }^{30}$ This classic stooped appearance of PD may be associated with cervical malalignment in the setting of relatively normal global sagittal alignment, which can result in significant difficulty with swallowing, excessive drooling, and limitations in horizontal gaze secondary to neck flexion. The ability to maintain an upright posture and horizontal gaze is fundamental in daily activities. ${ }^{18}$ Moreover, it can be challenging to correct global sagittal malalignment with spinal surgery in patients with PD, because of the complex combination of neuromuscular and degenerative diseases. Consequently, poor surgical outcome, need for revision surgery, and operative complications are more common in patients with PD., ${ }^{419,29}$ To help reduce these problems, preoperative evaluation should be done thoroughly and include assessment of both global spinal alignment and regional cervical alignment.

Recently, there has been increasing recognition of the importance of global sagittal spinopelvic malalignment as a source of significant pain, disability, and unfavorable health-related quality of life (HRQOL) in adults with spinal deformity. ${ }^{8,9,23-25}$ In addition, the spinal regions are not independent of one another, and cervical alignment has been shown to correlate with global sagittal spinopelvic alignment, thoracic kyphosis (TK), lumbar lordosis (LL), and pelvic morphology. ${ }^{1}$ Key measures of cervical alignment include cervical lordosis (C2-7 sagittal Cobb angle) and C2-7 sagittal vertical axis (SVA). The C2-7 sagittal Cobb angle may be used to define cervical kyphosis (CK), and the C2-7 SVA may be used to assess for cervical positive sagittal malalignment (CPSM). Regional cervical sagittal alignment has been shown to be important for the surgical outcome and severity of disability following cervical fusion surgery ${ }^{28}$ and has been shown to correlate with myelopathy severity among patients with cervical spondylotic myelopathy. ${ }^{26}$

Despite the significant functional and HRQOL impact of cervical deformity and the vulnerability of patients with PD to develop spinal deformities, the literature lacks a detailed assessment of cervical deformity in the setting of PD. Our objectives in the present study were twofold. First, we sought to identify the prevalence and characteristics of cervical deformity (CK and CPSM) in a cohort of PD patients. Second, we further investigated these deformities in the context of the overall global sagittal spinopelvic alignment and the severity of PD.

\section{Methods \\ Patient Population and Clinical Assessment}

This was a prospective, cross-sectional study based on 89 consecutive patients with idiopathic PD. Eighty-nine age- and sex-matched patients without PD who visited our outpatient clinic at Severance Hospital in Korea for degenerative cervical spine disease served as a comparison group. The control group patients will have cervical spine surgery after the first follow-up visit to the outpatient clinic in the future (in 2 years). Their preoperative radiographs were assessed for this study. The data for both groups were collected at a single neurology and neurosurgery outpatient clinic over a 12-month period. For the PD study group, we included patients who were more than 21 years old and had a diagnosis of PD based on the United Kingdom Parkinson's Disease Society Brain Bank criteria for PD. ${ }^{13}$ We excluded patients with atypical parkinsonism, secondary PD, or drug-induced PD. In addition, patients who had been treated with deep brain stimulation surgery and spinal surgery were excluded. The present study was approved by the institutional review board of Severance Hospital in Korea.

Clinical and demographic parameters including age, sex, duration of PD, time since diagnosis of PD, Unified Parkinson's Disease Rating Scale (UPDRS) score, Hoehn and Yahr (H\&Y) stage, history of back pain, history of levodopa (L-dopa) treatment, and history of spine surgery were collected. The UPDRS assesses the progression of $\mathrm{PD}$ and is the most commonly used scale in the clinical study of PD. ${ }^{11}$ The H\&Y stage is a commonly used system for describing how the symptoms of PD progress. ${ }^{10}$

\section{Radiographic Assessment}

Full-length standing lateral spine radiographs were used to assess C2-7 Cobb angle and C2-7 SVA (Fig. 1). C2-7 SVA was defined as the distance between the horizontal offset of the C-2 plumb line and the posterior superior corner of C-7. ${ }^{28}$ Radiographic measures were performed using standard techniques ${ }^{21}$ and included C7-S1 SVA, pelvic incidence (PI), pelvic tilt (PT), sacral slope, LL, and TK (measured from T-5 to T-12). Based on a previously reported threshold, CK was considered present when the C2-7 Cobb angle was a negative value. ${ }^{1}$ CPSM was considered present when the C2-7 SVA was higher than $4 \mathrm{~cm} .{ }^{28}$ In addition, PI-LL mismatch, PT modifiers, C7-S1 SVA modifiers, and PI-LL modifiers were assessed based on the Scoliosis Research Society (SRS)-Schwab adult thoracolumbar deformity classification. ${ }^{23}$ Demographic and clinical factors and radiographic measures were compared between the 2 groups for each deformity type (CK and CPSM).

\section{Statistical Analysis}

All statistical analyses were performed using SPSS version 18.0 software (SPSS Inc.). For categorical variables, cross-tabulations were generated, and Fisher exact or Pearson chi-square tests were used to compare the distributions. For continuous variables, nonparametric tests were used to investigate the differences between subsets of patients classified by categorical data. Pearson correlation analyses were used to assess the associations between continuous variables. Multiple linear regression analysis was performed to provide adjusted assessment of factors potentially associated with the presence of CK and CPSM in patients with PD. A p value of $<0.05$ was considered statistically significant.

\section{Results}

Table 1 summarizes the demographic and clinical char- 

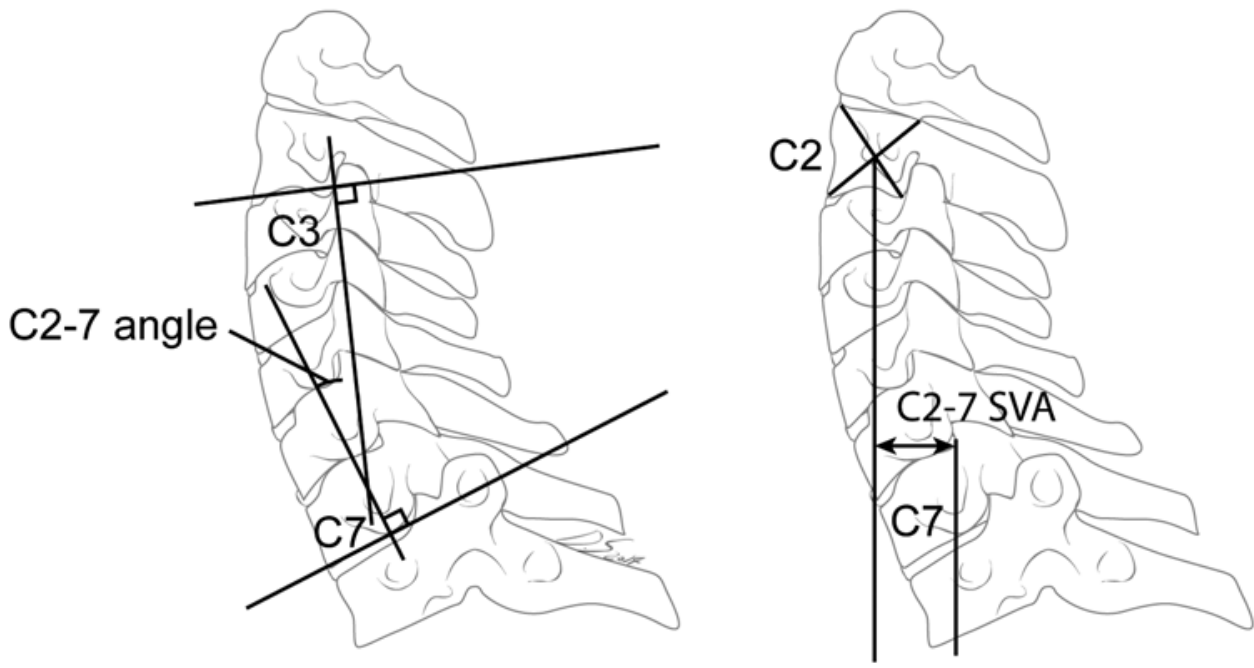

FIG. 1. Radiological assessment of C2-7 angle Cobb (left) and C2-7 SVA (right).

TABLE 1. Demographic and clinical characteristics of patients with PD and an age- and sex-matched control group

\begin{tabular}{|c|c|c|c|}
\hline Variable* & PD & Control Group & p Value† \\
\hline No. of patients & 89 & 89 & \\
\hline M:F ratio (\% female) & $41: 48(54)$ & $41: 48(54)$ & 1.000 \\
\hline Age in yrs (SD) & $68.1(8.74)$ & $68.1(8.57)$ & 0.966 \\
\hline CK $(\%)$ & $11(12.4)$ & $9(10.1)$ & 0.635 \\
\hline CPSM (\%) & $25(28.1)$ & $1(1.1)$ & $<0.001$ \\
\hline C2-7 Cobb angle in degrees (SD) & $16.9(13.80)$ & $10.7(9.12)$ & 0.001 \\
\hline C2-7 SVA in cm (SD) & $3.33(1.57)$ & $1.50(0.89)$ & 0.000 \\
\hline C7-S1 SVA in cm (SD) & $5.07(4.56)$ & $1.21(3.98)$ & $<0.001$ \\
\hline $\mathrm{Pl}$ in degrees (SD) & $50.1(10.6)$ & $52.8(7.7)$ & 0.065 \\
\hline PT in degrees (SD) & $23.3(11.3)$ & $17.9(9.3)$ & $<0.001$ \\
\hline SS in degrees (SD) & $28.5(8.9)$ & $34.3(8.5)$ & $<0.001$ \\
\hline LL in degrees (SD) & $37.6(14.3)$ & $29.5(11.6)$ & $<0.001$ \\
\hline TK in degrees (SD) & $34.6(13.8)$ & $28.6(10.33)$ & $<0.001$ \\
\hline PT modifier (\%) & & & 0.005 \\
\hline 0 & $35(39.3)$ & $57(64.0)$ & \\
\hline+ & $39(43.8)$ & $22(24.7)$ & \\
\hline++ & $14(15.7)$ & $10(11.2)$ & \\
\hline C7-S1 SVA modifier (\%) & & & $<0.001$ \\
\hline 0 & $46(51.7)$ & $70(78.7)$ & \\
\hline+ & $26(29.2)$ & 17 (19.1) & \\
\hline++ & $17(19.1)$ & $2(2.2)$ & \\
\hline PI-LL mismatch modifier (\%) & & & $<0.001$ \\
\hline 0 & $37(41.5)$ & $9(10.1)$ & \\
\hline+ & $18(20.2)$ & $34(38.2)$ & \\
\hline++ & $21(23.5)$ & $46(51.7)$ & \\
\hline
\end{tabular}

SS = sacral slope.

* PT, C7-S1, and PI-LL mismatch modifiers are based on the SRS-Schwab classification. ${ }^{23}$ Reported values for pelvic parameters are based on 76 patients due to the lack of sufficient visualization of the femoral heads on the radiographs of 13 patients. All values are means (SD) unless otherwise indicated.

† Statistically significant $p$ values are shown in boldface type. 
acteristics and the radiological parameters of both the PD and control patients. As expected based on matching, age and sex were not significantly different between the group of 89 patients with PD and the matched control group. The 89 patients with PD included 41 men and 48 women and had a mean age of 68.2 years (range $42-90$ years).

Of the 89 PD patients, 25 (28.1\%) had CPSM (C2-7 SVA $>4 \mathrm{~cm})$ and $11(12.4 \%)$ had CK (C2-7 Cobb angle $<$ $0^{\circ}$ ) (Table 1). However, in the control group, only $1(1.1 \%)$ had CPSM and $9(10.1 \%)$ had CK. Compared with the control group, there was a significantly higher prevalence of CPSM (28.1\% vs $1.1 \%, \mathrm{p}<0.001)$ but not of CK $(12.4 \%$ vs $10.1 \%, \mathrm{p}=0.635)$ in PD patients.

Overall, radiological parameters of the PD group tended to be very different from those of the control group, except for the PI (Table 1). Patients with PD had significantly higher PT $\left(23.3^{\circ}\right.$ vs $\left.17.9^{\circ}\right)$, LL $\left(37.6^{\circ}\right.$ vs $\left.29.5^{\circ}\right)$, TK $\left(34.6^{\circ}\right.$ vs $\left.28.6^{\circ}\right), \mathrm{C} 2-7 \mathrm{Cobb}$ angle $\left(16.9^{\circ}\right.$ vs $\left.10.7^{\circ}\right)$, and C7-S1 SVA $(3.33 \mathrm{~cm}$ vs $1.50 \mathrm{~cm})$. Based on the SRS-Schwab classification, patients with PD also had significantly higher PT modifier, C7-S1 SVA modifier, and PI-LL mismatch modifier compared with the matched control group ( $\mathrm{p}=$ $0.005,<0.001$, and $<0.001$, respectively). Approximately $60 \%$ of patients with PD had an abnormal PT modifier (+ or ++$)$. Nearly one-half $(48.3 \%)$ of the PD patients had an abnormal C7-S1 SVA modifier (+ or ++), and the PI-LL mismatch modifier was abnormal $(+$ or ++$)$ in just under one-half of the patients with PD.

Notably, there was no significant correlation between TK and C2-7 sagittal Cobb angle in PD (Fig. 2). However, the correlation between TK and C2-7 SVA was significant for both the PD and control patient groups (Fig. 3).

Demographic and clinical characteristics of 89 patients with $\mathrm{PD}$, stratified by the presence or absence of CK, are summarized in Table 2. The mean age of patients with CK was less than that of patients without CK (62.1 vs 69.0 years, $\mathrm{p}=0.013$ ). Patients with $\mathrm{CK}$ had a longer duration of PD than those without CK (56.4 vs 36.2 months, $\mathrm{p}=$ $0.034)$. However, the severity of PD was not significantly different between those with and without CK. Spinopelvic parameters did not differ in patients with PD based on the presence or absence of CK (Table 3). The best-fit model based on logistic regression analysis of factors potentially associated with the presence of CK included younger age,

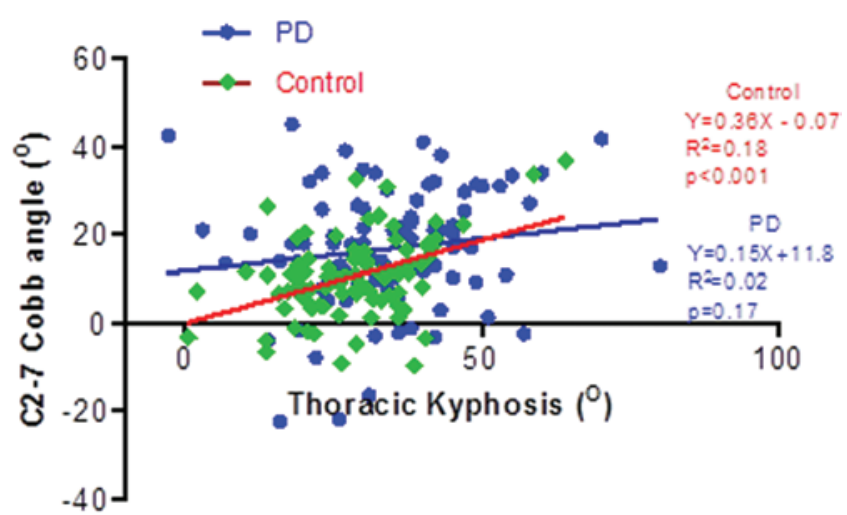

FIG. 2. Correlation between TK and C2-7 Cobb angle in PD patients and in an age- and sex-matched control group. Figure is available in color online only.

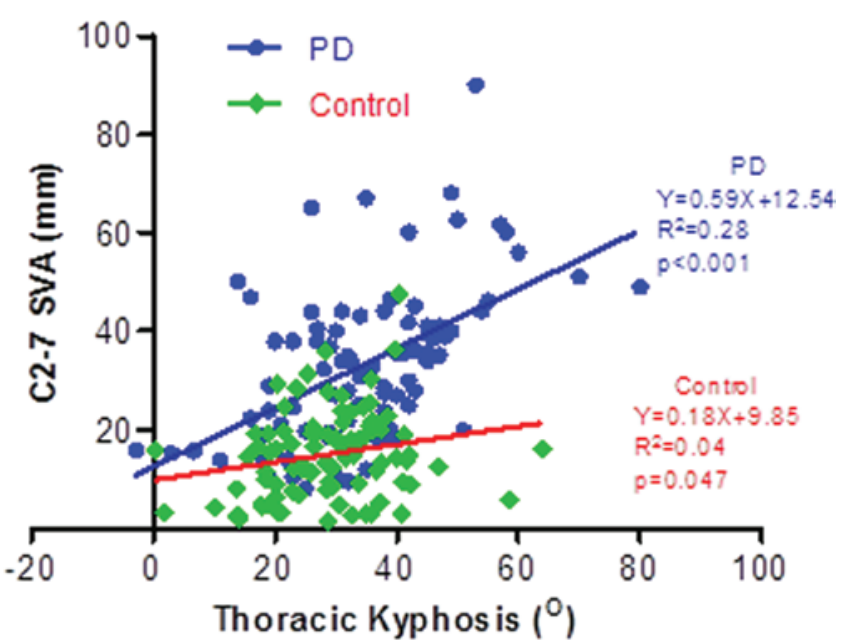

FIG. 3. Correlation between TK and C2-7 SVA in PD patients and in an age- and sex-matched control group; SVA. Figure is available in color online only.

worse PI-LL mismatch modifier, and better C7-S1 SVA modifier (Table 4).

Demographic and clinical characteristics of 89 patients with PD, stratified by the presence of CPSM, are summarized in Table 5. Patients with CPSM had a nonsignificant trend toward more advanced H\&Y stage (1.78 vs 1.47 , p $=0.05)$ compared with patients without CPSM. Spinopelvic parameters revealed that patients with CPSM only had significantly higher TK than those without CPSM (43.4 vs $31.1^{\circ}, \mathrm{p}<0.001$ ) (Table 6 ). The best-fit model on logistic regression analysis of factors potentially associated with

TABLE 2. Demographic and clinical characteristics of 89 patients with PD, stratified by presence or absence of $\mathrm{CK}^{*}$

\begin{tabular}{|c|c|c|c|}
\hline \multirow[b]{2}{*}{ Variable } & \multicolumn{2}{|c|}{ CK } & \multirow[b]{2}{*}{$\mathrm{p}$ Value } \\
\hline & No & Yes & \\
\hline No. of patients & 78 & 11 & \\
\hline Females (\%) & 56 & 36 & 0.333 \\
\hline Age in yrs (SD) & $69.0(8.1)$ & $62.1(10.9)$ & 0.013 \\
\hline Duration of PD in mos (SD) & $36.2(29.6)$ & $56.4(24.9)$ & 0.034 \\
\hline $\begin{array}{l}\text { Previously established/ } \\
\text { new diagnosis of PD at } \\
\text { presentation }\end{array}$ & $38 / 40$ & $5 / 6$ & 1.000 \\
\hline $\begin{array}{l}\text { Initial PD neurological } \\
\text { presentation (\%) }\end{array}$ & & & 0.349 \\
\hline Tremor & $26(33)$ & $2(18)$ & \\
\hline Rigidity & $32(41)$ & $4(36)$ & \\
\hline Mixed & $20(25.6)$ & $5(46)$ & \\
\hline H\&Y stage (SD) & $1.56(0.67)$ & $1.60(0.66)$ & 0.851 \\
\hline UPDRS score (SD) & $22.8(14.7)$ & $21.2(13.3)$ & 0.740 \\
\hline History of back pain (\%) & $27(34.6)$ & $6(54.5)$ & 0.067 \\
\hline $\begin{array}{l}\text { History of L-dopa treatment } \\
(\%)\end{array}$ & $51(65.4)$ & $8(72.7)$ & 0.131 \\
\hline History of spine surgery (\%) & $10(12.8)$ & $0(0)$ & 0.232 \\
\hline
\end{tabular}


TABLE 3. Sagittal spinopelvic radiographic parameters of 89 patients with $\mathrm{PD}$, stratified by presence or absence of $\mathrm{CK}$

\begin{tabular}{lccc}
\hline & \multicolumn{2}{c}{ CK } & \\
\cline { 2 - 3 } Variable* & No $(\mathrm{n}=78)$ & Yes $(\mathrm{n}=11)$ & p Value \\
\hline C7-S1 SVA in cm (SD) & $5.3(4.50)$ & $2.8(4.60)$ & 0.091 \\
\hline PI in degrees (SD) & $50.5(10.4)$ & $47.7(11.5)$ & 0.425 \\
\hline PT in degrees (SD) & $23.6(11.6)$ & $20.8(8.31)$ & 0.454 \\
\hline Sacral slope in degrees (SD) & $28.6(9.2)$ & $26.8(7.3)$ & 0.518 \\
\hline LL in degrees (SD) & $37.9(14.6)$ & $35.3(11.6)$ & 0.585 \\
\hline $\begin{array}{l}\text { Thoracic kyphosis in degrees } \\
\text { (SD) }\end{array}$ & $35.2(13.9)$ & $30.2(12.7)$ & 0.264 \\
\hline PI-LL mismatch modifier in & $12.4(15.3)$ & $12.3(14.7)$ & 0.988 \\
degrees (SD) & & & \\
\hline PT modifier (\%) & & & 0.704 \\
\hline 0 & $31(40.7)$ & $4(36.4)$ & \\
\hline+ & $33(43.4)$ & $6(54.5)$ & \\
\hline++ & $13(17.1)$ & $1(9.1)$ & \\
\hline C7-S1 SVA modifier (\%) & & & \\
\hline 0 & $38(48.7)$ & $9(81.8)$ & \\
\hline+ & $24(30.8)$ & $1(9.1)$ & \\
\hline++ & $16(20.5)$ & $1(9.1)$ & \\
\hline PI-LL mismatch modifier (\%) & & & \\
\hline 0 & $35(44.9)$ & $4(36.4)$ & \\
\hline+ & $15(19.7)$ & $3(27.3)$ & \\
\hline++ & $17(22.3)$ & $4(36.4)$ & \\
\hline
\end{tabular}

* Modifiers are based on the SRS-Schwab classification. ${ }^{23}$ Reported values for pelvic parameters are based on 76 patients due to the lack of sufficient visualization of the femoral heads on the radiographs of 13 patients. All values are means $(\mathrm{SD})$ unless otherwise indicated.

the presence of CPSM included male sex, higher TK, and more advanced H\&Y stage (Table 7).

\section{Discussion}

Recently, several reports have demonstrated that cervical deformity significantly correlates with HRQOL.,26-28 In the present study, patients with PD were significantly

TABLE 4. Logistic regression analysis of demographic and clinical factors for cervical kyphosis in 89 patients with PD

\begin{tabular}{lccc}
\hline \multicolumn{1}{c}{ Variable* $^{*}$} & $\begin{array}{c}\text { Unstandardized } \\
\text { Coefficients (B) }\end{array}$ & $\begin{array}{c}\text { Standardized } \\
\text { Coefficients (b) }\end{array}$ & $\begin{array}{c}p \\
\text { Value† }\end{array}$ \\
\hline Sex (M = 1, F = 2) $\neq$ & -1.439 & 0.237 & 0.183 \\
\hline Age (yrs) & -0.103 & 0.902 & $\mathbf{0 . 0 4 7}$ \\
\hline Duration of PD (mos) & 0.028 & 1.029 & 0.094 \\
\hline TK $\left(^{\circ}\right)$ & 0.031 & 1.032 & 0.493 \\
\hline PT modifier & -0.113 & 0.893 & 0.890 \\
\hline PI-LL mismatch modifier & 2.548 & 12.785 & $\mathbf{0 . 0 1 5}$ \\
\hline C7-S1 SVA modifier & -2.015 & 0.133 & $\mathbf{0 . 0 3 0}$
\end{tabular}

* Modifiers are based on the SRS-Schwab classification. ${ }^{23}$

$\dagger$ Statistically significant $p$ values are shown in boldface type.

‡ For logistic regression analysis, male and female are classified as 1 and 2 .

Negative B value means that males are more at risk than females.
TABLE 5. Demographic and clinical characteristics of 89 patients with PD, stratified by presence or absence of CPSM ${ }^{*}$

\begin{tabular}{|c|c|c|c|}
\hline \multirow[b]{2}{*}{ Variable } & \multicolumn{2}{|c|}{ CPSM } & \multirow{2}{*}{$\begin{array}{c}p \\
\text { Value† }\end{array}$} \\
\hline & No & Yes & \\
\hline No. of patients & 64 & 25 & \\
\hline Females (\%) & 61 & 36 & 0.057 \\
\hline Mean age in yrs (SD) & $67.8(7.9)$ & $69.0(10.5)$ & 0.541 \\
\hline Duration of PD in mos (SD) & $39.5(30.5)$ & $36.4(27.8)$ & 0.654 \\
\hline $\begin{array}{l}\text { Previously established/new diag- } \\
\text { nosis of PD at presentation }\end{array}$ & $32 / 32$ & $14 / 11$ & 0.611 \\
\hline $\begin{array}{l}\text { Initial PD neurological presenta- } \\
\text { tion (\%) }\end{array}$ & & & 0.312 \\
\hline Tremor & $18(28.1)$ & $10(40.0)$ & \\
\hline Rigidity & $29(45.3)$ & $7(28.0)$ & \\
\hline Mixed & $17(26.6)$ & $8(32.0)$ & \\
\hline H\&Y stage (SD) & $1.47(0.57)$ & $1.78(0.81)$ & 0.05 \\
\hline UPDRS score (SD) & $20.7(15.5)$ & $26(11.8)$ & 0.152 \\
\hline History of back pain (\%) & $21(32.8)$ & $12(48.0)$ & 0.105 \\
\hline History of L-dopa treatment (\%) & $42(65.6)$ & $17(68.0)$ & 0.493 \\
\hline History of spine surgery (\%) & $7(10.9)$ & $3(12.0)$ & 0.843 \\
\hline
\end{tabular}

* All values are means (SD) unless otherwise indicated.

† Statistically significant $p$ values are shown in boldface type.

more likely to have global and regional sagittal spinal malalignment compared with an age- and sex-matched patient group with degenerative cervical disease but without PD. Among the patients with PD, the prevalence of global positive sagittal malalignment $(\mathrm{C} 7-\mathrm{S} 1 \mathrm{SVA} \geq 4 \mathrm{~cm})$ was $48.3 \%$ and of CPSM was $28.1 \%$. Nearly $30 \%$ of the PD patients had CPSM, while only about $1 \%$ of the degenerative cervical disease patients without PD had CPSM, and almost $50 \%$ of the patients with PD had global positive sagittal malalignment, while only about $20 \%$ of the degenerative cervical disease patients without PD had global positive sagittal malalignment. These data strongly suggest that PD has a significant negative effect on the alignment of the entire spine axis from the lower lumbosacral area to the cervical spine.

Patients with PD tend to have a weaker posterior muscular tension band and a generally flexed and stooped posture that increases with disease severity. ${ }^{19}$ Previous studies of PD have noted cervical deformities, including antecollis (drop head syndrome), which is a variant of the cervical "bent spine" syndrome. Antecollis has been attributed to involuntary cervical muscle contraction causing neck flexion, but it may also be due to neck extensor muscle myopathy. ${ }^{17,22}$ Cervical deformity may accompany neck flexion as a result of the involuntary muscle spasm or due to secondary or associated degenerative joint disease of the cervical spine. In the context of muscle spasm, MRI of drop head syndrome demonstrated a diffuse muscular edema of the neck extensor muscles on fat-suppressed T2-weighted images (STIR), as well as the enhancement of these muscles after administration of gadolinium on T1-weighted images. ${ }^{3,7,16,17}$ Electromyography of the neck extensor muscles (C5-T1) and the trapezius muscles re- 
TABLE 6. Sagittal spinopelvic radiographic parameters of 89 patients with PD, stratified based on presence or absence of CPSM

\begin{tabular}{lccr}
\hline & \multicolumn{2}{c}{ CPSM } & \\
\cline { 2 - 3 } Variable* & No $(\mathrm{n}=64)$ & Yes $(\mathrm{n}=25)$ & p Value \\
\hline C7-S1 SVA in cm (SD) & $4.76(4.46)$ & $5.86(4.81)$ & 0.308 \\
\hline PI in degrees (SD) & $50.2(10.2)$ & $49.7(11.5)$ & 0.862 \\
\hline PT in degrees (SD) & $24.1(11.8)$ & $21.1(9.45)$ & 0.256 \\
\hline Sacral slope in degrees (SD) & $28.2(9.21)$ & $28.8(8.32)$ & 0.781 \\
\hline LL in degrees (SD) & $36.8(14.7)$ & $39.6(13.2)$ & 0.414 \\
\hline TK in degrees (SD) & $31.1(12.2)$ & $43.4(13.9)$ & $<0.001$ \\
\hline PI-LL mismatch modifier in & $13.7(15.7)$ & $9.13(13.5)$ & 0.233 \\
degrees (SD) & & & \\
\hline PT modifier (\%) & & & 0.155 \\
\hline 0 & $24(37.5)$ & $11(44.0)$ & \\
\hline+ & $26(41.3)$ & $13(52.0)$ & \\
\hline++ & $13(20.3)$ & $1(4.0)$ & \\
\hline C7-S1 SVA modifier (\%) & & & \\
\hline 0 & $36(56.3)$ & $11(44.0)$ & \\
\hline+ & $17(26.6)$ & $8(32.0)$ & \\
\hline++ & $11(17.2)$ & $6(24.0)$ & \\
\hline PI-LL mismatch modifier (\%) & & & \\
\hline 0 & $27(42.2)$ & $12(48.0)$ & \\
\hline+ & $14(21.8)$ & $4(16.0)$ & \\
\hline++ & $15(23.4)$ & $6(24.0)$ & \\
\hline & & & \\
\hline
\end{tabular}

* Modifiers are based on the SRS-Schwab classification. ${ }^{23}$ Reported values for pelvic parameters are based on 76 patients due to lack of sufficient visualization of the femoral heads on the radiographs of 13 patients. All values are means (SD) unless otherwise indicated.

$\dagger$ Statistically significant $p$ values are shown in boldface type.

vealed a myopathic pattern. ${ }^{3,7,16,17}$ The diagnosis of a focal myositis was confirmed by a biopsy of the trapezius muscle, splenius capitis, or semispinalis capitis muscles, and the muscle biopsy revealed necrosis of muscle fibers, myophagia, and T-cell infiltrates., $3,16,17$ Therefore, the flexed or dropped head posture that may afflict patients with PD may be attributed at least in part to involuntary cervical muscle contraction with net neck flexion due to neck extensor muscle myopathy. ${ }^{3}$

In the present study, a significantly higher prevalence of CPSM was found in the PD group than the control group, but a similar difference was not identified with regard to the prevalence of CK. Cervical extensor muscles play a role in preventing significant kyphotic changes in cervical alignment. ${ }^{14}$ However, to date, most studies of cervical muscles involved in cervical alignment have been performed with the focus on CK, not CPSM. Therefore, we do not clearly know which muscles may be specifically associated with CK versus CPSM. Based on the higher prevalence of CPSM in PD patients, it is possible that the neuromuscular impact of PD may preferentially involve musculature more relevant to the development of CPSM than that of CK.

The cervical spine is an adaptive segment, which changes relative to the other spinal segments in an effort to maintain the head over the pelvis and to maintain
TABLE 7. Logistic regression analysis of demographic and clinical factors for CPSM in 89 patients with PD

\begin{tabular}{lccc}
\hline \multicolumn{1}{c}{ Variables } & $\begin{array}{c}\text { Unstandardized } \\
\text { Coefficients }(\mathrm{B})\end{array}$ & $\begin{array}{c}\text { Standardized } \\
\text { Coefficients }(\mathrm{b})\end{array}$ & $\mathrm{p} \mathrm{Value} \dagger$ \\
\hline Sex $(\mathrm{M}=1, \mathrm{~F}=2) \ddagger$ & -1.766 & 0.171 & $\mathbf{0 . 0 3 3}$ \\
\hline Age $(\mathrm{yrs})$ & -0.021 & 0.979 & 0.584 \\
\hline H\&Y stage & 1.302 & 3.676 & $\mathbf{0 . 0 2 9}$ \\
\hline TK $\left(^{\circ}\right)$ & 0.099 & 1.104 & $\mathbf{0 . 0 0 3}$ \\
\hline PT modifier & -0.301 & 0.740 & 0.664 \\
\hline PI-LL mismatch modifier & 0.926 & 2.524 & 0.174 \\
\hline C7-S1 SVA modifier & -0.153 & 0.858 & 0.828 \\
\hline
\end{tabular}

${ }^{*}$ Modifiers are based on the SRS-Schwab classification. ${ }^{23}$

$\dagger$ Statistically significant $p$ values are shown in boldface type.

$\ddagger$ For logistic regression analysis, male and female are classified as 1 and 2 .

Negative B value means that males are more at risk than females.

a horizontal gaze. ${ }^{1,12,27}$ Also, in the setting of global positive sagittal malalignment, cervical lordosis tends to increase to maintain a horizontal gaze. ${ }^{27}$ Therefore, we may hypothesize that the neuromuscular pathology of PD that affects cervical posture may induce CPSM earlier and the compensatory mechanisms for maintaining horizontal gaze (typically increased cervical extension and lordosis) reduce the likelihood of developing CK. However, this compensatory mechanism is also negatively affected by PD. While C2-7 SVA compensates to remain relatively stable as TK increases in the control group to prevent forward pitching (CPSM), PD patients do not appear to demonstrate a similar ability to compensate and are thus more prone to develop CPSM (Figs. 3 and 4). On the other hand, based on the correlation between $\mathrm{C} 2-7$ Cobb angle and TK (Figs. 2 and 4), the C2-7 Cobb angle increases with TK for both the PD and control groups. In other words, cervical lordosis similarly increases with increases in TK in each group, resulting in no statistically significant difference in the prevalence of CK between the 2 groups. This may explain why a horizontal gaze was maintained in both patient groups.

CPSM was associated with advanced PD (higher $\mathrm{H} \& \mathrm{Y}$ stage) in this study. Antecollis has been reported to be more common in patients with advanced PD whose prominent Parkinson's signs were rigidity and akinesia. ${ }^{6,15}$ Findings from the present study suggest that CPSM occurs often in advanced PD, while occurrence of CK may be less tied to the pathology of PD than it is to the general changes of increased age and sagittal spinal malalignment (PI-LL mismatch, C7-S1 SVA). This finding suggests that there may be a different pathogenesis of CPSM and CK, at least among patients with PD.

The most recognized abnormal posture of PD patients is the classic stooped simian appearance, with flexion of the hips and knees, and rounding of the shoulders. ${ }^{5}$ In the present study, radiological parameters can help to represent and explain this classic stooped appearance. PD patients had higher PT, higher LL, higher TK, and higher cervical lordosis compared with patients without PD. Also, measures of global and regional sagittal spinal alignment, including measures of cervical alignment, are important factors that may impact postoperative pain and disability 


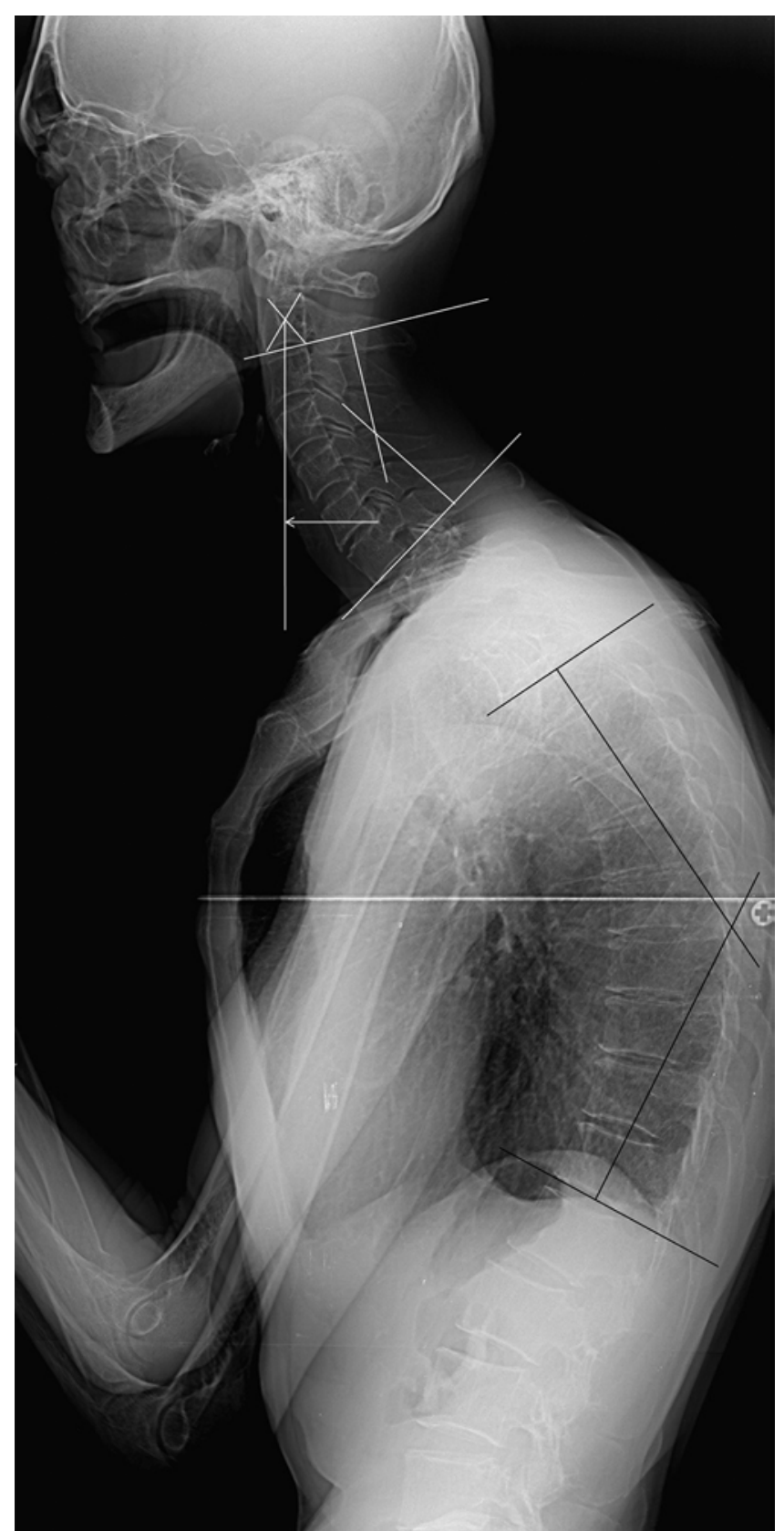

FIG. 4. Representative case of a PD patient. A 69-year-old man had a 78-month history of PD, H\&Y Stage 3, UPDRS score of 46 , history of L-dopa treatment, and no history of spine surgery. A sagittal full-length standing radiograph shows higher TK, cervical lordosis, and CPSM; TK $=62.8^{\circ}, \mathrm{C} 2-7 \mathrm{Cobb}$ angle $=34.1^{\circ}, \mathrm{C} 2-7 \mathrm{SVA}=4.11 \mathrm{~cm}(\mathrm{CPSM})$

in spinal surgery. It can be very challenging to correct global sagittal malalignment for PD patients with spinal surgery and to achieve a durable surgical outcome. The findings of the present study may prove useful for clinical evaluation in the neurology clinic and, if indicated, for operative planning in the surgical clinic.

Strengths of the present study include the relatively large number of patients who were collected consecutively and that assessment of these patients included full-length standing radiographs. In addition, an age- and sex-matched cohort without PD was used as a control group for compar- ison. On the other hand, the control group was not asymptomatic, and that is a limitation of this paper. However, we wish to insist that PD patients had more cervical deformity than degenerative cervical disease patients without PD who had worse cervical spine than normal asymptomatic people. Another limitation of the present study is the lack of neck-specific measures of HRQOL (e.g., Neck Disability Index), which precludes the ability to assess the potential clinical impact of the cervical deformities identified. Future studies to assess correlation between clinical symptoms and these cervical deformities are warranted.

\section{Conclusions}

Patients with PD have a significantly higher prevalence of CPSM compared with age- and sex-matched control patients with cervical degenerative disease but without PD. Among patients with $\mathrm{PD}, \mathrm{CK}$ is not associated with the severity of PD but is associated with overall global sagittal malalignment. In contrast, the presence of CPSM is associated more with the severity of PD than it is with the presence of global sagittal malalignment. Collectively, these data suggest that the neuromuscular pathogenesis of PD may affect the development of CPSM more so than that of CK.

\section{Acknowledgments}

This work was supported by a 2012 Inje University research grant and a grant from the Korean Health Technology R\&D Project, Ministry of Health \& Welfare, Republic of Korea (A1202541201-0000300).

\section{References}

1. Ames CP, Blondel B, Scheer JK, Schwab FJ, Le Huec JC, Massicotte EM, et al: Cervical radiographical alignment: comprehensive assessment techniques and potential importance in cervical myelopathy. Spine (Phila Pa 1976) 38 (22 Suppl 1):S149-S160, 2013

2. Ashour R, Jankovic J: Joint and skeletal deformities in Parkinson's disease, multiple system atrophy, and progressive supranuclear palsy. Mov Disord 21:1856-1863, 2006

3. Askmark H, Eeg-Olofsson K, Johansson A, Nilsson P, Olsson Y, Aquilonius S: Parkinsonism and neck extensor myopathy: a new syndrome or coincidental findings? Arch Neurol 58:232-237, 2001

4. Babat LB, McLain RF, Bingaman W, Kalfas I, Young P, Rufo-Smith C: Spinal surgery in patients with Parkinson's disease: construct failure and progressive deformity. Spine (Phila Pa 1976) 29:2006-2012, 2004

5. Doherty KM, van de Warrenburg BP, Peralta MC, SilveiraMoriyama L, Azulay JP, Gershanik OS, et al: Postural deformities in Parkinson's disease. Lancet Neurol 10:538-549, 2011

6. Fujimoto K: Dropped head in Parkinson's disease. J Neurol 253 (Suppl 7):VII21-VII26, 2006

7. Gaeta M, Mazziotti S, Toscano A, Rodolico C, Mazzeo A, Blandino A: "Dropped-head" syndrome due to isolated myositis of neck extensor muscles: MRI findings. Skeletal Radiol 35:110-112, 2006

8. Glassman SD, Berven S, Bridwell K, Horton W, Dimar JR: Correlation of radiographic parameters and clinical symptoms in adult scoliosis. Spine (Phila Pa 1976) 30:682-688, 2005

9. Glassman SD, Bridwell K, Dimar JR, Horton W, Berven S, Schwab F: The impact of positive sagittal balance in adult 
spinal deformity. Spine (Phila Pa 1976) 30:2024-2029, 2005

10. Goetz CG, Poewe W, Rascol O, Sampaio C, Stebbins GT, Counsell C, et al: Movement Disorder Society Task Force report on the Hoehn and Yahr staging scale: status and recommendations. Mov Disord 19:1020-1028, 2004

11. Goetz CG, Tilley BC, Shaftman SR, Stebbins GT, Fahn S, Martinez-Martin P, et al: Movement Disorder Society-sponsored revision of the Unified Parkinson's Disease Rating Scale (MDS-UPDRS): scale presentation and clinimetric testing results. Mov Disord 23:2129-2170, 2008

12. Hilibrand AS, Tannenbaum DA, Graziano GP, Loder RT, Hensinger RN: The sagittal alignment of the cervical spine in adolescent idiopathic scoliosis. J Pediatr Orthop 15:627632,1995

13. Hughes AJ, Daniel SE, Kilford L, Lees AJ: Accuracy of clinical diagnosis of idiopathic Parkinson's disease: a clinicopathological study of 100 cases. J Neurol Neurosurg Psychiatry 55:181-184, 1992

14. Iizuka H, Nakajima T, Iizuka Y, Sorimachi Y, Ara T, Nishinome M, et al: Cervical malalignment after laminoplasty: relationship to deep extensor musculature of the cervical spine and neurological outcome. J Neurosurg Spine 7:610-614, 2007

15. Kashihara K, Ohno M, Tomita S: Dropped head syndrome in Parkinson's disease. Mov Disord 21:1213-1216, 2006

16. Kastrup A, Gdynia HJ, Nägele T, Riecker A: Dropped-head syndrome due to steroid responsive focal myositis: a case report and review of the literature. J Neurol Sci 267:162-165, 2008

17. Katz JS, Wolfe GI, Burns DK, Bryan WW, Fleckenstein JL, Barohn RJ: Isolated neck extensor myopathy: a common cause of dropped head syndrome. Neurology 46:917-921, 1996

18. Klineberg E, Schwab F, Smith JS, Gupta MC, Lafage V, Bess S: Sagittal spinal pelvic alignment. Neurosurg Clin N Am 24:157-162, 2013

19. Koller H, Acosta F, Zenner J, Ferraris L, Hitzl W, Meier O, et al: Spinal surgery in patients with Parkinson's disease: experiences with the challenges posed by sagittal imbalance and the Parkinson's spine. Eur Spine J 19:1785-1794, 2010

20. Marsden CD, Duvoisin R: Scoliosis and Parkinson's disease. Arch Neurol 37:253-254, 1980

21. O'Brien MF, Kuklo TR, Blanke KM, Lenke LG (eds): Radiographic Measurement Manual. Memphis: Medtronic Sofamor Danek, 2004

22. Oerlemans WG, de Visser M: Dropped head syndrome and bent spine syndrome: two separate clinical entities or different manifestations of axial myopathy? J Neurol Neurosurg Psychiatry 65:258-259, 1998

23. Schwab F, Ungar B, Blondel B, Buchowski J, Coe J, Deinlein D, et al: Scoliosis Research Society-Schwab adult spinal deformity classification: a validation study. Spine (Phila Pa 1976) 37:1077-1082, 2012

24. Schwab FJ, Blondel B, Bess S, Hostin R, Shaffrey CI, Smith JS, et al: Radiographical spinopelvic parameters and disability in the setting of adult spinal deformity: a prospective multicenter analysis. Spine (Phila Pa 1976) 38:E803-E812, 2013

25. Smith JS, Klineberg E, Schwab F, Shaffrey CI, Moal B, Ames CP, et al: Change in classification grade by the SRSSchwab Adult Spinal Deformity Classification predicts impact on health-related quality of life measures: prospective analysis of operative and nonoperative treatment. Spine (Phila Pa 1976) 38:1663-1671, 2013
26. Smith JS, Lafage V, Ryan DJ, Shaffrey CI, Schwab FJ, Patel AA, et al: Association of myelopathy scores with cervical sagittal balance and normalized spinal cord volume: analysis of 56 preoperative cases from the AOSpine North America Myelopathy study. Spine (Phila Pa 1976) 38 (22 Suppl 1):S161-S170, 2013

27. Smith JS, Shaffrey CI, Lafage V, Blondel B, Schwab F, Hostin R, et al: Spontaneous improvement of cervical alignment after correction of global sagittal balance following pedicle subtraction osteotomy. J Neurosurg Spine 17:300-307, 2012

28. Tang JA, Scheer JK, Smith JS, Deviren V, Bess S, Hart RA, et al: The impact of standing regional cervical sagittal alignment on outcomes in posterior cervical fusion surgery. Neurosurgery 71:662-669, 2012

29. Upadhyaya CD, Starr PA, Mummaneni PV: Spinal deformity and Parkinson disease: a treatment algorithm. Neurosurg Focus 28(3):E5, 2010

30. van de Warrenburg BP, Cordivari C, Ryan AM, Phadke R, Holton JL, Bhatia KP, et al: The phenomenon of disproportionate antecollis in Parkinson's disease and multiple system atrophy. Mov Disord 22:2325-2331, 2007

\section{Disclosures}

Justin Smith: Consultant: Biomet, Medtronic, DePuy, Globus; honoraria for educational courses: Biomet, Medtronic, DePuy, Globus; Research support: DePuy, AOSpine NA; Fellowship support: AOSpine NA, NREF. Christopher Shaffrey: Biomet: patent; Medtronic: royalties, consultant; Globus: consultant; NuVasive: consultant; Depuy: consultant. Virginie Lafage: Nemaris: board membership, stock; MSD: consultant, payment for lectures; DePuy: research grant, payment for lectures; ISSG: research grant; SRS: research grant; AOSpine: research grant; K2M: payment for lectures. Frank Schwab: Nemaris: board membership, stock; MSD: consultant, payment for lectures, patent, royalties; DePuy: consultant, payment for lectures; ISSG: research grant; SRS: research grant; AOSpine: research grant. Christopher Ames: DePuy: consultant; Stryker: consultant; Medtronic: consultant; UCSF: employment; Trans 1: research grant, payment for lectures, payment for manuscript preparation; Fish \& Richardson PC: patent; Lanx: royalties; Aesculap: royalties; Visualase: stock; Doctors Research Group: stock; Trans 1: stock.

\section{Author Contributions}

Conception and design: Ha, Moon, Baik. Acquisition of data: Ha, Moon, Baik. Analysis and interpretation of data: Ha, Moon, Smith. Drafting the article: Moon, Smith. Critically revising the article: Ha, Moon, Smith, Ames, Shaffrey. Reviewed submitted version of manuscript: Moon, Smith, Ames, Shaffrey, Lafage, Schwab, Matsumoto, Baik. Statistical analysis: Moon. Study supervision: Ha.

\section{Supplemental Information \\ Current Affiliations}

Dr. Moon: Department of Neurosurgery, Chonnam National University Hospital and Medical School, Gwangju, Korea.

\section{Correspondence}

Yoon Ha, Department of Neurosurgery, Yonsei University College of Medicine, 50 Yonsei-ro, Seodaemun-gu, Seoul 120-752, Korea.email: hayoon@yuhs.ac. 